\title{
Bioprosthetic mitral valve thrombosis less than one year after replacement and an ablative MAZE procedure: a case report
}

\author{
Omar Saeed ${ }^{1 *}$, Byron R Williams $\mathrm{Jr}^{2}$, Melvin $\mathrm{Ku}^{3}$, Omar M Lattouf ${ }^{4}$
}

\begin{abstract}
Occurrence of bioprosthetic valve thrombosis less than a year after replacement is very uncommon. Here, we describe a case of a 57 year old male, who presented 10 months after receiving a bioprosthetic mitral valve replacement with a two week history of dyspnea on exertion, worsening orthopnea and decreased exercise tolerance. Echocardiography revealed severe mitral regurgitation (MR), thrombosis of the posterior mitral leaflet, left atrial (LA) mural thrombus and a depressed left ventricular ejection fraction of twenty-five percent. Given severe clot burden and decompensated heart failure (New York Heart Association - NYHA class III) repeat sternotomy was done to replace the bioprosthetic mitral valve and remove LA mural thrombus. MR was resolved postoperatively. This brief report further reviews promoting factors, established guidelines and management strategies of bioprosthetic valve thrombosis.
\end{abstract}

\section{Background}

Bioprosthetic mitral valves are advantageous over mechanical valves as their incidence of thrombosis, pannus formation and embolic events are significantly lower. This disparity in thromboembolic events as compared to mechanical valves avoids a need for chronic anticoagulation in many patients receiving bioprosthetic valve replacement [1]. However, bioprosthetic mitral valves can present with thrombosis shortly after replacement in high risk patients not maintained on anticoagulation, leading to severe valve incompetence and cardiac decompensation, as noted in the following case.

\section{Case Presentation}

A 57 year old male with a past medical history of chronic atrial fibrillation, a depressed ejection fraction of $25 \%$, and severe MR underwent mitral valve replacement with a bioprosthetic Mosaic valve (Medtronic Inc., Minneapolis MN) and a complete left and right sided MAZE procedure. Post operative transthoracic echocardiogram (TTE) showed a competent mitral valve tissue prosthesis and the patient was discharged on warfarin. Anticoagulation was discontinued three months after

\footnotetext{
* Correspondence: osaeed@emory.edu

'Department of Medicine, Emory University, Atlanta, Ga, USA
}

valve replacement and the patient remained in sinus rhythm on electrocardiography.

Ten months following mitral valve replacement, the patient presented with a two week history of progressive dyspnea on exertion, orthopnea and weight gain. TTE revealed severe mitral valve stenosis and mitral regurgitation, with a mean gradient of $8.5 \mathrm{mmhg}$ (max. gradient $-25.5 \mathrm{mmhg}$ ) across the mitral valve, and restricted motion of mitral leaflets. On transesophageal echocardiogram (TEE), a mitral mass was observed on the posterior leaflet along with mural thrombus in a dilated left atrium measuring $4.90 \mathrm{~cm}$ in diameter (figure 1). Ejection fraction was $25 \%$. The patient was started on intervenous diuretics and anticoagulation with Heparin, however due to severity of clot burden and progressive decompensated heart failure (NYHA class III) repeat sternotomy was performed.

Intraoperatively, mural clot was debrided from the free and posterior left atrial walls. The mitral bioprosthesis was incompetent with pannus growing on the posterior leaflet. This valve was excised and replaced with a 25 mm On-X mechanical valve (On-X Life Technologies, Inc., Austin TX.) that functioned without leakage after placement. Postoperatively, the patient had improved exercise tolerance and was discharged on indefinite warfarin therapy. 


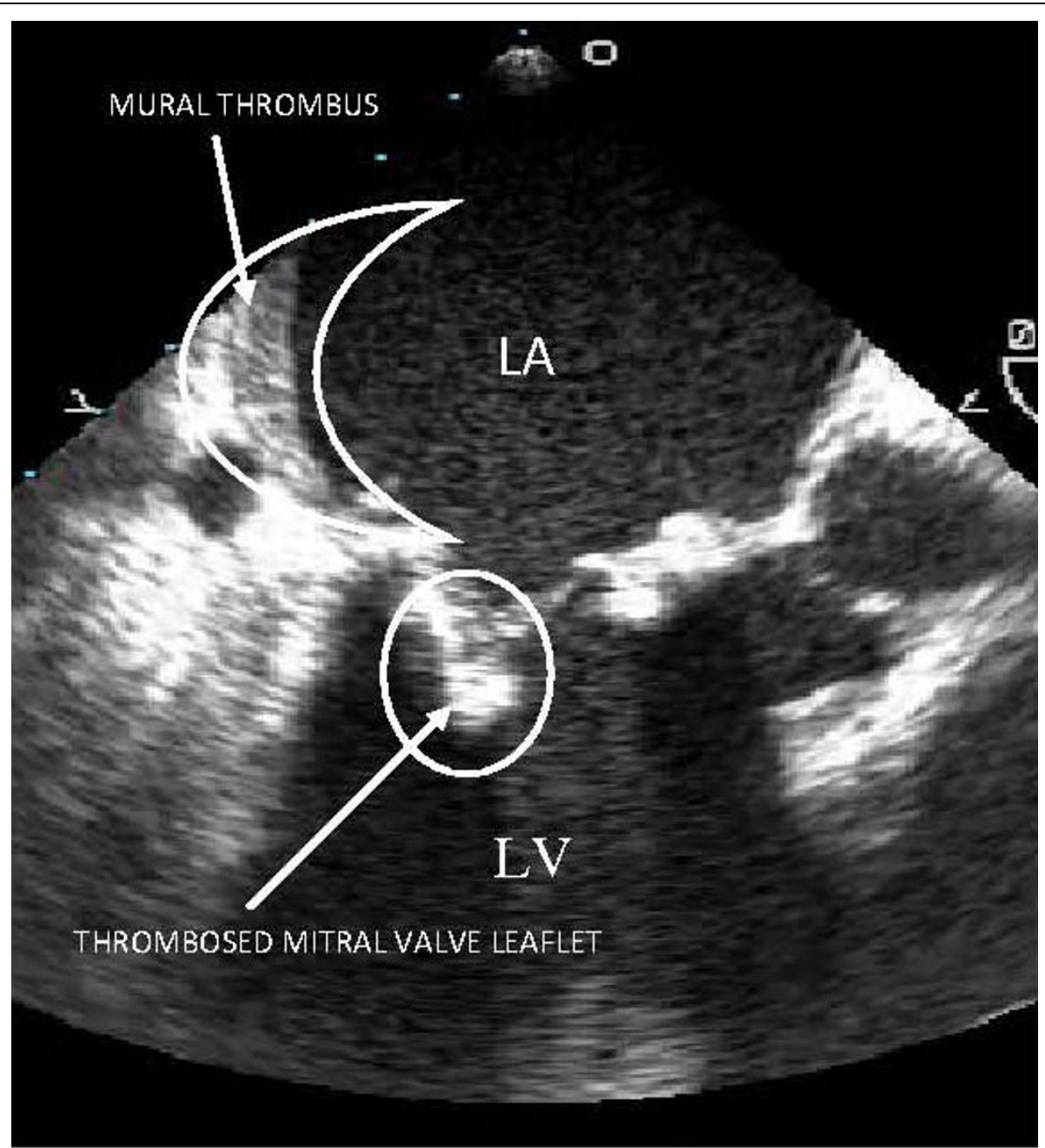

Figure 1 TEE showing mural thrombus in the left atrium and a thrombosed bioprosthetic mitral valve.

\section{Discussion}

Clinically significant bioprosthetic valve thrombosis is considered uncommon, however, its incidence on routine echocardiographic surveillance is reported as high as six percent [2]. Specific risk factors that promote formation of bioprosthetic valve thrombosis include large LA size, atrial fibrillation leading to decreased transvalvular flow, decreased LVEF, prior history of thromboembolic events and a hypercoagulable diathesis [3-5]. In the present case, two risk factors were present including an enlarged LA measuring $4.90 \mathrm{~cm}$ in diameter and a decreased EF of $25 \%$. Moreover, radioablative MAZE lines are areas of damaged LA endothelium which can serve as a nidus for thrombus formation. Due to the presence of several prothrombotic risk factors prolonged anticoagulation with warfarin could have assisted in prevention of thrombus formation and valve dysfunction.

Although freedom from long term anticoagulation is a feature of bioprosthetic valve replacement, this case calls for a brief review of current anticoagulation guidelines following bioprosthetic valve replacement and a radioablative MAZE procedure. The 2008 American Heart Association (AHA) and American College of Cardiology (ACC) guidelines state that high risk patients with any of the following risk factors including atrial fibrillation, LV dysfunction with $\mathrm{EF}<30 \%$, recurrent thromboembolic events or a hypercoagulable condition meet a class I indication for indefinite anticoagulation [6]. To reduce the risk of thrombus formation after a radio ablative procedure for atrial fibrillation the 2007 Heart Rhythm Society (HRS) expert consensus statement recommends a minimum two month period of warfarin anticoagulation that should be continued indefinitely if the patient's $\mathrm{CHADS}_{2}$ score is greater or equal to 2 [7]. These guidelines further emphasize a beneficial role of prolonged anticoagulation in high risk patients.

This case also calls for frequent post operative echocardiographic monitoring in non- anticoagulated 
patients with risk factors promoting valve thrombosis. The 2007 European Society of Cardiology (ESC) guidelines [8] recommend initial follow up 6-12 weeks post operatively with TTE imaging. Thereafter, yearly clinical assessment is prudent and repeat TTE imaging is dependent on development of new cardiac symptoms. TEE can be considered if TTE is of poor quality, in cases of suspected prosthetic valve dysfunction or endocarditis. However, this case illustrates that high risk patients not on prolonged anticoagulation can develop significant thrombus and valve dysfunction prior to becoming symptomatic. More frequent clinical cardiac assessment and/or TTE imaging in high risk asymptomatic patients might allow earlier detection of bioprosthetic valve dysfunction by clot formation.

According to the 2007 ESC guidelines [8], once valve thrombosis reaches clinically significant obstruction, management between anticoagulation and surgery rests on the level of critical illness. Surgery is performed in critically ill patients unless it is not immediately available or in patients unlikely to survive surgery due to significant co-morbidities, where fibrinolysis is considered as an alternative. In non-critically ill patients, if their baseline degree of anticoagulation was inadequate then heparin and aspirin are initiated and thrombus is reassessed by echocardiography. If there is no resolution of valve thrombosis then surgery versus fibrinolysis is considered. In cases of persistent or recurrent valve thrombosis despite adequate anticoagulation surgical replacement is performed.

Management of non-obstructive prosthetic valve thrombosis depends on the occurrence of thromboembolism (TE) and thrombus size [8]. Initially, anticoagulation is optimized. In patients with evidence of $\mathrm{TE}$, surgery is performed immediately if thrombus size is $>10 \mathrm{~mm}$, otherwise it is delayed. In patients without TE, surgery is performed for persistent thrombus of $>10$ $\mathrm{mm}$ on adequate anticoagulation and fibrinolysis is considered in high risk patients with multiple co morbidities.

In the present case, obstructive valve thrombosis, large clot burden and critical illness made surgical replacement a reasonable and successful treatment option.

\section{Conclusion}

Bioprosthetic mitral valve thrombosis is an under recognized complication in high risk patients that leads to rapid valve incompetence. Post-operatively, patients must be stratified in high or low risk categories, and anticoagulation should be maintained indefinitely for high risk patients. If anticoagulation is not maintained for individualized reasons then a semi-annual TTE within the first year and annually thereafter may detect subclinical bioprosthetic valve thrombosis in asymptomatic patients.

\section{Consent}

Written informed consent was obtained from the patient for publication of this case report and accompanying images. A copy of the written consent is available for review by the Editor-n-Chief of this journal.

\section{Author details}

'Department of Medicine, Emory University, Atlanta, Ga, USA. ${ }^{2}$ Division of Cardiology, Emory University, Atlanta, Ga, USA. ${ }^{3}$ Department of Medicine, Michigan State University, East Lansing, MI, USA. ${ }^{4}$ Division of Cardiothoracic Surgery, Emory University, Atlanta, Ga, USA.

\section{Authors' contributions}

OS: Resident physician, provided pre-operative care and primary author. BRW: Cardiologist, provided pre-operative care and advice during the manuscript writing process.

MK: Assisted in writing and preparing manuscript.

OL: Cardiothoracic Surgeon, performed the bioprosthetic valve repair and provided advice during the manuscript writing process.

All authors have read and approve the final manuscript.

\section{Competing interests}

OML discloses that he has served as a consultant and received research grants from Medtronic Corporation and On-X Life Technologies. The rest of the authors declare that they do not have any competing interests.

Received: 22 January 2010 Accepted: 29 March 2010

Published: 29 March 2010

\section{References}

1. Nakao M, Lim SL, Chua YL: Bioprosthetic mitral valve thrombosis in a patient in sinus rhythm after the radiofrequency maze procedure. $J$ Thorac Cardiovasc Surg 2006, 132(6):1464-5.

2. Oliver JM, Galloge P, Gonzalez A, Dominguez FJ, Gamallo C, Mesa JM: Bioprosthetic mitral valve thrombosis: clinical profile, Transesophageal echocardiographic features, and follow-up after anticoagulant therapy. J Am Soc Echocardiogr 1996, 9:691-9.

3. Stein PD, Alpert JS, Dalen JE, Horstkotte D, Turpie AG: Antithrombotic therapy in patients with mechanical and biological prosthetic heart valves. Chest 1998, 114(suppl 5):602S-10S

4. Thomas B, Carreras F, Borras X, Pons-Lladó G: An unusual case of bioprosthetic mitral valve thrombosis. Ann Thorac Surg 2001, 72:259-61.

5. Korkolis DP, Passik CS, Marshalko SJ, Koullias GJ: Early bioprosthetic mitral valve "pseudostenosis" after complete preservation of the native mitral apparatus. Ann Thorac Surg 2002, 74:1689-91.

6. Bonow RO, Carabello BA, Chatterjee K, de Leon AC Jr, Faxon DP, Freed MD, Gaasch WH, Lytle BW, Nishimura RA, O'Gara PT, O'Rourke RA, Otto CM, Shah PM, Shanewise JS: 2008 focused update incorporated into the ACC/ AHA 2006 guidelines for the management of patients with valvular heart disease: a report of the American College of Cardiology/American Heart Association Task Force on Practice Guidelines (Writing Committee to revise the 1998 guidelines for the management of patients with valvular heart disease). Endorsed by the Society of Cardiovascular Anesthesiologists, Society for Cardiovascular Angiography and Interventions, and Society of Thoracic Surgeons. J Am Coll Cardiol 2008, 52(13):e1-142.

7. Calkins H, Brugada J, Packer DL, Cappato R, Chen SA, Crijns HJ, Damiano RJ $J$, Davies DW, Haines DE, Haissaguerre M, lesaka Y, Jackman W, Jais P, Kottkamp H, Kuck KH, Lindsay BD, Marchlinski FE, McCarthy PM, Mont JL, Morady F, Nademanee K, Natale A, Pappone C, Prystowsky E, Raviele A, Ruskin JN, Shemin RJ: HRS/EHRA/ECAS expert Consensus Statement on catheter and surgical ablation of atrial fibrillation: recommendations for personnel, policy, procedures and follow-up. A report of the Heart 
Rhythm Society (HRS) Task Force on catheter and surgical ablation of atrial fibrillation. Heart Rhythm 2007, 4(6):816-61.

8. Vahanian A, Baumgartner $H, B a x ~ J$, Butchart E, Dion R, Filippatos $G$, Flachskampf F, Hall R, lung B, Kasprzak J, Nataf P, Tornos P, Torracca L, Wenink A, Guidelines on the management of valvular heart disease: The Task Force on the Management of Valvular Heart Disease of the European Society of Cardiology. Eur Heart J 2007, 28(2):230-68.

doi:10.1186/1749-8090-5-18

Cite this article as: Saeed et al: Bioprosthetic mitral valve thrombosis

less than one year after replacement and an ablative MAZE procedure: a case report. Journal of Cardiothoracic Surgery 2010 5:18.

Submit your next manuscript to BioMed Central and take full advantage of:

- Convenient online submission

- Thorough peer review

- No space constraints or color figure charges

- Immediate publication on acceptance

- Inclusion in PubMed, CAS, Scopus and Google Scholar

- Research which is freely available for redistribution

Submit your manuscript at www.biomedcentral.com/submit 